\title{
A STUDY OF ASSOCIATION OF CLINICAL PROFILE WITH HISTOPATHOLOGY OF ORAL SQUAMOUS CELL CARCINOMA
}

\author{
Dr.S.Selvi ${ }^{1}$,Dr. N.Andal ${ }^{2}$, Dr.V.Ramya ${ }^{3}$, Dr.B.Pushpa ${ }^{4}$ and Dr.R.Geetha ${ }^{5}$ \\ ${ }_{1,3}$ (Department Of Pathology, Assistant Professor,Kilpauk Medical College, The Tamilnadu Dr.MGR Medical \\ University, India) \\ ${ }^{2,4}$ (Department Of Pathology, Professor, Kilpauk Medical College, The Tamilnadu Dr.MGR Medical \\ University, India) \\ ${ }_{5}^{5}$ (Department of Pathology, Professor and HOD, Kilpauk Medical College, The Tamilnadu Dr.MGR Medical \\ University, India).
}

\begin{abstract}
Oral cancer is one of the most common cancer and constitute a major public health problem. The purpose of the study was to evaluate the clinical profile of patients with oral squamous cell carcinoma for gender, age, primary site and histological grading. Four hundred and five biopsy proven cases of oral squamous cell carcinoma were included in this study. It was conducted over a period of two years from Jan 2015 to Dec 2016 in the Department of Oncology Government Royapettah Hospital, Chennai. The peak incidence was seen in forth and fifth decade of life with male to female ratio was about 2.6:1. Well differentiated squamous cell carcinoma was assigned in $86.2 \%$ of cases and most common site of involvement was the lateral border of tongue.
\end{abstract}

Keywords: Oral, tobacco, squamous cell carcinoma,tongue.

\section{Introduction}

Oral cancer is one of the ten most common cancer. Its high frequency is in central and south east asian countries has been well documented. In Indian subcontinent a high incidence of oral cancer arise in areas of leukoplakia. Oral cancer includes a group of neoplasm affecting any region of the oral cavity, pharyngeal regions and salivary glands. Oral squamous cell carcinoma represents the most frequent of all oral neoplasms. It is estimated that more of $90 \%$ of all oral neoplasms are oral squamous cell carcinoma.[1] Oral cancer have a multifaceted etiology.[2] Severe alcoholism, use of tobacco like cigarettes, smokeless tobacco, betel nut chewing and human papilloma virus(HPV) are the most common risk factors for oral cancer.[3,4] Noted that the lateral margin of the tongue as the most frequent intraoral site. A high incidence of oral cancer, arise in areas of leukoplakia. Regardless of the easy access of oral cavity for clinical examination, oral squamous cell carcinoma usually diagnosed in advance stages. The purpose of the study was to evaluate the clinical profile of patients with oral squamous cell carcinoma.

\section{Materials And Methods}

A retrospective study of 482 patients with oral cavity lesions was carried out in the Department of Oncology, Government Royapettah Hospital, over a period of Jan 2015 to Dec 2016. A total of 405 cases had squamous cell carcinoma of tongue, followed by buccal mucosa, alveolus, palate, lip and floor of mouth were included using purposive sampling technique and histopathologically confirmed oral carcinoma patients were included in this study. Specimen was collected and histopathological report was done in the department of pathology. Lesions with histological findings that were not compatible with OSCC were excluded from the study. The data pertaining to these patients were included such as age, gender, site of the lesion and histologically grading of tumour. The total sample size was grouped into seven age groups ranging from 21 years to 80 years. [Table 3] A statistical analysis was done on the data collected and the results were formulated.

\section{Results}

Two hundred and ninety four cases $(72.6 \%)$ of OSCC were observed in male and one hundred and eleven cases (27.4\%) were seen in female with a Male: female ratio of 2.6:1 and with the largest number of OSCCs developing in the fourth and fifth decades of life. Among the 405 cases of OSCC, we found 171 cases (42.2\%) involving most commonly the tongue, followed by 144 cases (35.6\%) buccal mucosa, 40 cases (9.9\%)alveolus, 23 cases (5.7\%)palate, 21 cases $(5.2 \%)$ lip and 6 cases (1.4\%) affecting floor of the mouth.

When anatomical sites were analyzed, the most commonly affected site was the left lateral border the tongue (91 cases, $53.2 \%$ ), followed by left side of buccal mucosa (74 cases, 51.3\%). When histological grading of the squamous cell carcinoma was compared, we noticed that 349 cases $(86.2 \%)$ were well-differentiated carcinoma, 39 cases $(9.6 \%)$ were moderately differentiated squamous cell carcinoma, 15 cases $(3.7 \%)$ were 
poorly differentiated carcinoma and 2 cases $(0.5 \%)$ were undifferentiated carcinoma.[Table 2] We have noticed that one patient diagnosed with OSCC had a synchronous primary carcinoma in the forehead subcutaneous plane and scalp. Despite small tumor size, regional and distant metastatic disease has developed in $6.7 \%$ of patients with tumor less than $1 \mathrm{~cm}$ size.

\section{Discussion}

Squamous cell carcinoma can occur anywhere in the oral cavity, but certain sites are more frequent. The carcinoma of the tongue represents $25 \%$ to $50 \%$ of all cases of OSCC [5] with the lateral borders being the most commonly affected locations. The mortality from squamous cell carcinoma is dependent on primary site in the mouth, with the lowest mortality from lip and floor of mouth cancer and the highest for cancer of the tongue. Cancers in the oral cavity are almost more likely to be localised at the time of diagnosis.

Gross appearance correlates with the clinical presentation of OSCC. The cut surface of the carcinoma is usually grey white, [Fig 1] sometimes with areas of necrosis and hemorrhage. The tumors vary in size from less than $1 \mathrm{~cm}$ to $5-6 \mathrm{cms}$. There are two basic histological behaviour either minimally invasive or widely invasive squamous cell carcinoma. Adipose tissue and skeletal muscle has little resistance to local invasion, with the time periosteum and bone cortex are breached, then the marrow is invaded by tumor. Lymph node involvement correlates with tumor size, depth of invasion and primary tumor site. Increased risk of nodal metastases with the more posterior site and tumor grade. Lung, bone and liver are the most common site for distant metastases from OSCC.

The microscopic features are similar to squamous cell carcinoma arising in other mucosal site. Dysplastic squamous epithelium or insitu carcinoma may be seen at the edge of early lesion. Infiltration of the stroma is assessed by an increase in tumour cell size, pleomorphism, irregularity and loss of epithelial stromal junction, stromal desmoplasia and inflammation. High mitotic activity, infiltrative borders, lymphatics and vascular invasion indicates aggressive behaviour. OSCC may be graded according to their degree of differentiation, mitotic activity and other factors. Grade I carcinomas are the most differentiated and Grade III, the least differentiated. The higher the grade the worse is the prognosis. Well differentiated carcinoma form broad bands and nests. The tumor cells have abundant eosinophilic cytoplasm, intercellular bridges and prominent keratinisation either as single cell keratinisation or keratin whorls. [Fig2] Grade II squamous cell carcinoma resembles squamous epithelial cells, but there is less evidence os squamous differentiation and less keratinisation than those in Grade I carcinoma. Grade III has infrequent keratinisation, cellular pleomorphism, increased mitosis, bizarre tumor giant cells and even mitotic spindling are prominent. Otherwise, poorly differentiated squamous cell carcinoma have sheets of uniform cells either small, large or spindle cell type.

Prognosis dependent on several factors, stage of carcinoma, site of primary tumor and histological grade. The stage of oral carcinoma is assigned by using TNM classification. Pathological stage I carcinoma are upto $2 \mathrm{~cm}$ in greatest diameter. Stage II carcinoma are larger upto $4 \mathrm{~cm}$ in diameter. Stage III carcinoma are greater than $4 \mathrm{~cm}$ diameter or have single ipsilateral lymph node involvement, whereas Stage IV carcinoma invades adjacent structures such as soft tissue and cortical bone and exhibit more extensive lymph node involvement. Epidemiology studies have shown that the sites of occurrence for oral cancer differ widely. Tongue, buccal mucosa, alveolus, palate, lip and floor of the mouth are in an ascending order of occurrence of OSCC in the oral cavity.[6,7] The worldwide epidemiological studies done on tongue squamous cell carcinoma.[Table 4] Mehrota et al.[8] found 42.6\%, Agarwal et al [9]found 16.2\% and Shenoi et al.[7] found $18.3 \%$ cases involving tongue , while Selvamani et al.[10] found 54 cases (14.1\%) involving tongue OSCC in his study. In our study, we found that 171 OSCC cases $(42.2 \%)$ were involving tongue. This variation could be due to various factors like level of exposure to carcinogens, geographic region set up, socioeconomic status and community awareness.

Albuquerque et al [11] found 59.7\% involving lateral borders of the tongue were the most frequent carcinoma. These results are similar to present study results, as we also found a most frequent site to be the lateral border of tongue and accounts for about $42.2 \%, 171$ cases out of 405 studied.

\section{Conclusion}

Largest number of Oral squamous cell carcinoma noted in the fourth and fifth decades of life with a male to female ratio was $2.6: 1$. The most common primary site of occurrence of squamous cell carcinoma was the lateral border of tongue followed by buccal mucosa, alveolus, palate, lip and floor of mouth respectively.

\section{References}

[1]. Chois S, Myers JN. Molecular pathogenesis or oral squamous cell carcinoma: Implications for therapy. J Dent Res. 2008; 87: 1432.

[2]. WarnakulaSuriya S. Causes of oral cancer - an appraisal of controversies. Br Dent J 2009; 207: 471-5.

[3]. Anil K. Chaturvedi, William F. Anderson, Joannie Lortet-Tieulent, Maria Paula Curado, Jacques Ferlay, Silvia Franceschi, Philip S.

[4]. Rosenberg, Freddie Bray, and Maura L. Gillison, "Worldwide Trends in Incidence Rates for Oral Cavity and Oropharyngeal Cancers" 
[5]. PLopez Jornet,* FJ Gomez Garcia,* M Lucero Berdugo,* F Parra Perez,* A Pons-Fuster Lopez, "Mouth self-examination in a population at risk of oral cancer"

[6]. Dantas DD, Ramos CC, Costa AL, Souza LB, Pinto LP. Clinicalpathological parameters in squamous cell carcinoma of the tongue. Braz Dent J. 2003;14: 22-5.

[7]. Barasch A, Morse DE, Krutchkoff DJ, Eisenberg E. Smoking, gender, and age a risk factors for site - specific intraoral squamous cell carcinoma. Cancer.1994; 73:509-13.

[8]. Shenoi R, Devrukhkar V, Chaudhuri, Sharma BK, Sapre Sb, Chikhale A. Demographic and clinical profile of oral squamous cell carcinoma patients: A retrospective study. Indian J Cancer. 2012; 49:21-6.

[9]. Mehrotra R, Singh M, Kumar D, Pandey AN, Gupta RK, Sinha US. Age specific incidence rate and pathological spectrum of oral cancer in Allahabad. Ind J Med Sci. 2003;57: 400-4.

[10]. Agarwal, AK, Sethi A, Sareen D, Dhingra S. Oral and oropharyngeal squamous cell carcinoma in our population: The clinicpathological and morphological description of 153 cases. Int. J. Morphol. 2011;29:686-93.

[11]. Selvamani, M. et al. "Prevalence of Oral Squamous Cell Carcinoma of Tongue in and around Davangere, Karnataka, India: A Retrospective Study over 13 Years.” Journal of Pharmacy \& Bioallied Sciences 7.Suppl 2 (2015): S491-S494.

[12]. Albuquerque R, López-López J, Marí-Roig A, Jané-Salas E, Roselló-Llabrés X, Santos JR. Oral Tongue Squamous Cell Carcinoma (OTSCC): Alcohol and Tobacco Consumption versus Non-Consumption. A Study in a Portuguese Population. Braz Dent J. $2011 ; 22: 517-521$.

\begin{tabular}{|l|l|l|l|}
\hline S.NO & SITE & $\begin{array}{l}\text { NO OF } \\
\text { CASES }\end{array}$ & PERCENTAGE \\
\hline 1 & Tongue & 171 & $42.2 \%$ \\
\hline 2 & Buccal Mucosa & 144 & $35.6 \%$ \\
\hline 3 & Alveolus & 40 & $9.9 \%$ \\
\hline 4 & Palate & 23 & $5.7 \%$ \\
\hline 5 & Lip & 21 & $5.2 \%$ \\
\hline 6 & Floor of mouth & 6 & $1.4 \%$ \\
\hline & TOTAL & 405 & \\
\hline
\end{tabular}

Table 1: Primary Site Of Oral Squamous Cell Carcinoma N=405

Table 2: Histological Grading Of Squamous Cell Carcinoma Cases Studied N=405

\begin{tabular}{|l|l|l|}
\hline State Of Differentiation & Number Of Cases & Percentage \\
\hline Well Differentiated & 349 & $86.2 \%$ \\
\hline Moderately Differentiated & 39 & $9.6 \%$ \\
\hline Poorly Differentiated & 15 & $3.7 \%$ \\
\hline Undifferentiated & 2 & $0.5 \%$ \\
\hline Total & 405 & \\
\hline
\end{tabular}

Table 3: Age Distribution Of Patients with Oscc ( N\%)

\begin{tabular}{|l|l|l|l|}
\hline AGE GROUP & MALES & FEMALES & TOTAL \\
\hline $21-30$ yrs & $16(3.9)$ & $4(1.0)$ & $20(4.9)$ \\
\hline $31-40$ yrs & $41(10.1)$ & $11(2.7)$ & $52(12.8)$ \\
\hline $41-50$ yrs & $94(23.2)$ & $29(7.2)$ & $123(30.4)$ \\
\hline $51-60$ yrs & $77(19.0)$ & $39(9.6)$ & $116(28.6)$ \\
\hline $61-70$ yrs & $54(13.3)$ & $25(6.2)$ & $79(19.5)$ \\
\hline $71-80$ yrs & $12(3.0)$ & $3(0.7)$ & $15(3.7)$ \\
\hline TOTAL & $294(72.6)$ & $111(27.4)$ & $405(100)$ \\
\hline
\end{tabular}

OSCC- oral squamous cell carcinoma

Table 4: Comparison Of Studies Of Oscc

\begin{tabular}{|l|l|l|}
\hline REFERENCES & (TONGUE ) OSCC \% & YEAR \\
\hline Mehrota et al $^{8}$ & 129 cases (42.6) & 2003 \\
\hline Agarwal et al $^{9}$ & 18 cases (16.2) & 2011 \\
\hline Shenoi et al $^{7}$ & 54 cases (18.3) & 2012 \\
\hline Selvamani et al & 54 cases (14.1) & 2014 \\
\hline Present study & 171 cases (42.2) & 2017 \\
\hline
\end{tabular}


Fig 1; Gross Picture -Carcinoma Tongue- involving left lateral border

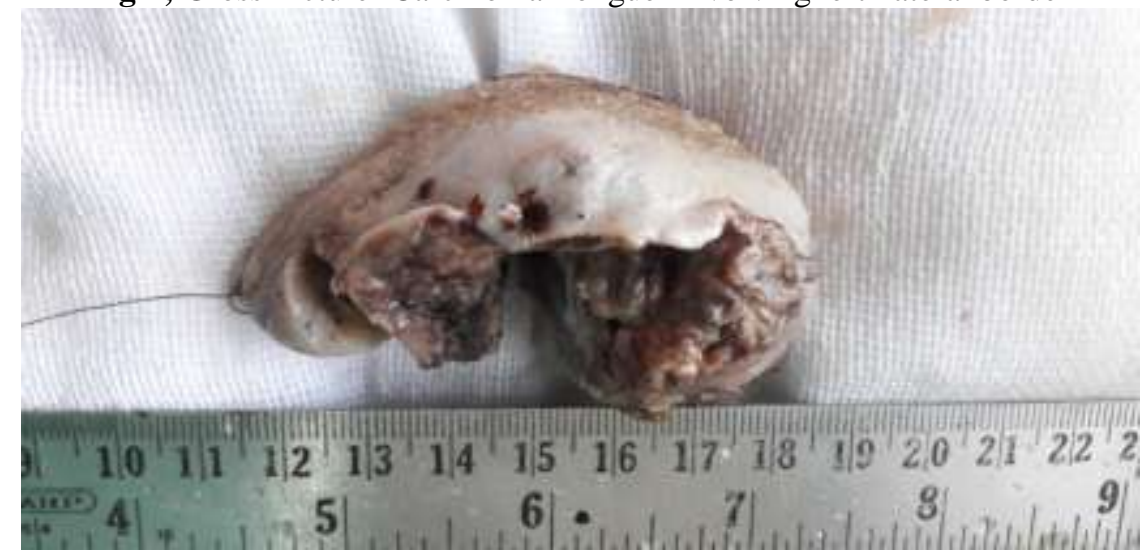

Fig 2- Hpex10- Well Differentiated Squamous Cell Carcinoma

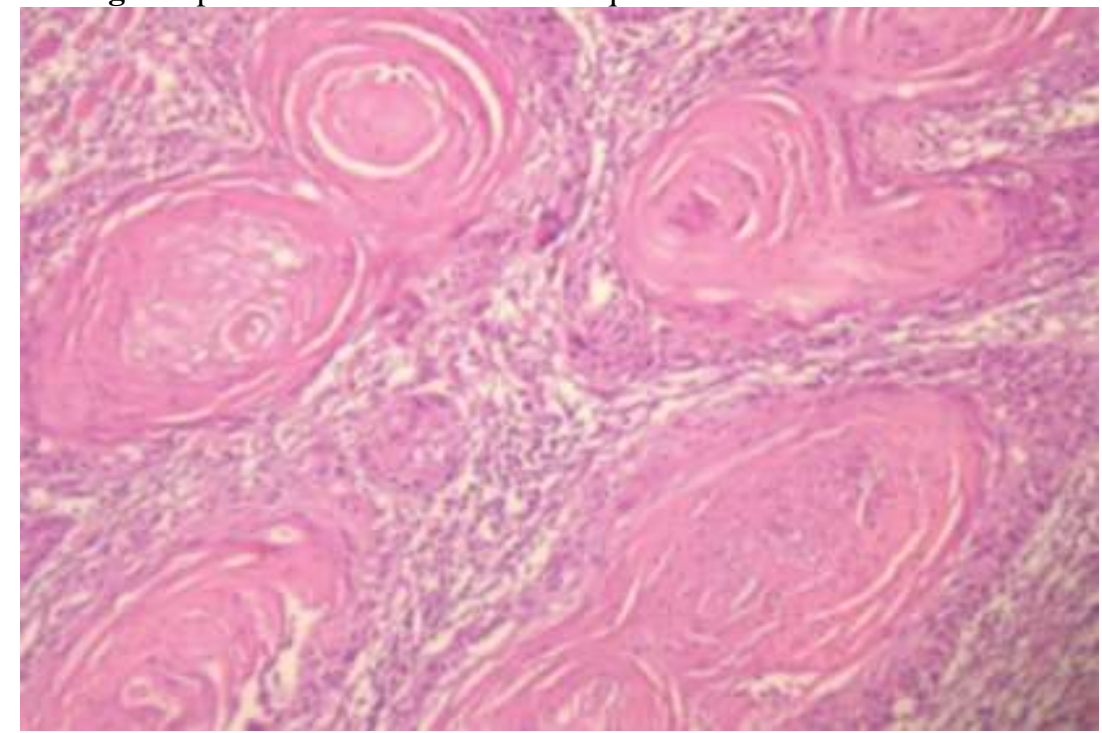

